\title{
Are the doctors of the future ready to support breastfeeding? A cross-sectional study in the UK
}

\author{
Kirsty V. Biggs ${ }^{*}$ (D), Katy J. Fidler², Natalie S. Shenker ${ }^{3}$ and Heather Brown ${ }^{2}$
}

\begin{abstract}
Background: Currently there is no published data on the inclusion of breastfeeding education within the UK medical school curriculum. This study aims to address this knowledge gap and explore students' perceptions of their readiness to support breastfeeding.

Methods: An online survey was used to collect data from 32 UK undergraduate medical schools and their students. All students in their final two years of study at the 30 universities offering a 5- or 6-year medicine course, were eligible.

Results: Curriculum data was obtained from $26(81 \%)$ institutions. Compulsory breastfeeding education was provided by $85 \%(N=22)$ institutions with $81 \%(n=21)$ providing lecture-based teaching and $19 \%(n=5)$ offering formal clinical education. Overall, 411 students from 22 institutions participated. A moderate ability to identify the benefits of breastfeeding was observed; however, self-rated confidence in practical skills was poor. Assisting with latching was the least confident skill, with confidence in only 3\% (14/411) students. Most students (93\%) viewed doctors as playing an important role in breastfeeding, with those interested in either women's health, paediatrics or general practice perceiving the role of doctors as more important. Overall, 93\% (381/411) students requested further breastfeeding education.

Conclusions: This study suggests UK medical schools are not adequately preparing students to support breastfeeding patients. Further studies should explore the competency of doctors to meet the needs of lactating women, and design optimal training for UK medical students.
\end{abstract}

Keywords: Medical education, Breastfeeding, Clinical skills, Medical training

\section{Background}

Over the course of human evolution, breastfeeding has played a pivotal role, with established benefits for the short- and long-term health of the mother and child [1, 2]. Far from simple nutrition, breastmilk is a complex bioactive fluid and developmental patterning tool, affecting cognition, immune maturation and physiology [3]. The

\footnotetext{
*Correspondence: Kirsty.biggs@uhnm.nhs.uk

Natalie S. Shenker and Heather Brown as joint last author

${ }^{1}$ Royal Stoke University Hospital, Newcastle Road, Stoke-on-Trent ST4 6QG, UK

Full list of author information is available at the end of the article
}

World Health Organization recommendations are that infants should be exclusively breastfed for around 6 months, continuing for two years and beyond, as long as mother and baby wish. In the UK, less than $1 \%$ of mothers are breastfeeding by the time their baby is one year [4].

The Unicef Baby Friendly Initiative is a global endeavour that seeks to entrench breastfeeding as a public health target, explicitly stating that all healthcare staff should be trained in the necessary skills to support breastfeeding [5].

Clinicians can be highly influential figures when parents are making decisions about infant feeding; however

(c) The Author(s). 2020 Open Access This article is licensed under a Creative Commons Attribution 4.0 International License, which permits use, sharing, adaptation, distribution and reproduction in any medium or format, as long as you give appropriate credit to the original author(s) and the source, provide a link to the Creative Commons licence, and indicate if changes were made. The images or other third party material in this article are included in the article's Creative Commons licence, unless indicated otherwise in a credit line to the material. If material is not included in the article's Creative Commons licence and your intended use is not permitted by statutory regulation or exceeds the permitted use, you will need to obtain permission directly from the copyright holder. To view a copy of this licence, visit http://creativecommons.org/licenses/by/4.0/ The Creative Commons Public Domain Dedication waiver (http://creativecommons.org/publicdomain/zero/1.0/) applies to the data made available in this article, unless otherwise stated in a credit line to the data. 
international data from a Cochrane review suggests that doctors rarely receive appropriate training to support and manage issues related to breastfeeding $[6,7]$. In the $\mathrm{UK}$, there is no standardised breastfeeding education for clinicians $[8,9]$. This lack of education is also reflected overseas with less than $10 \%$ of general practitioners (GP) in an Irish study [10], and less than 50\% of GP trainees in Australia receiving formal breastfeeding training [11].

There are several examples in the literature of where poor knowledge and training around infant feeding has been shown to have negative impacts. In a Norwegian survey of GPs, only $26 \%$ could identify the differences between infant formula and human milk, which consequently affected their confidence in counselling patients [12]. Furthermore, approximately half of GPs and paediatricians surveyed in the UK advised parents to introduce solids before the WHO/UNICEF recommendation of around 6 months [13]. Mothers who were inappropriately recommended by paediatricians to supplement with infant formula are more likely to have discontinued breastfeeding by 12 weeks [14].

Medical school builds the foundation for all doctors' clinical practice and is a perfect opportunity to educate future clinicians with the essential skills and knowledge to support their patients $[15,16]$. Furthermore, it could be argued that regardless of which specialty pathway the medical graduate follows, they are likely to have contact with breastfeeding patients during their hospital and community training. Currently there is no published data on infant feeding education provided within undergraduate medicine courses in the UK. International surveys suggest that medical students are not well enough equipped with the counselling skills and knowledge to support breastfeeding mothers [17-19].

This study aimed to collect data on the inclusion of breastfeeding education within the undergraduate curriculum at UK medical schools and to explore student perceptions of their role as future doctors in supporting breastfeeding.

\section{Methods}

\section{Study design}

A cross-sectional study was conducted to collect data on the delivery of teaching around breastfeeding within the undergraduate medical school curriculum and explore medical student perceptions on breastfeeding education using two separate online survey tools.

\section{Medical school recruitment}

Within the UK, 34 medical schools provide undergraduate teaching. Two medical schools are exclusively for postgraduate students and were excluded from our study. Of the 32 remaining, 30 provide a 5- or 6-year complete curriculum. The remaining two provide only 2 years of preclinical teaching. All 32 medical schools were invited through email to partake in an online survey on the inclusion of breastfeeding education within their undergraduate curriculum. Medical school curriculum support staff were emailed with a brief background, inviting them to participate in an online questionnaire. Consent was confirmed by participation and the right to withdraw was explained. Data for the student surveys was analysed only for the 30 medical schools with a full 5 or 6 year curriculum.

\section{Medical student recruitment}

All undergraduate students in their final 2 years of study at the 30 UK medical schools offering a 5- or 6-year medicine course were eligible for participation in an online medical student survey. Gatekeeper approval was sought from each eligible medical school to gain consent before students were contacted. A standardised message was sent to university staff and internal ethics applications were made depending on the framework of the medical school.

A standardised message, participant information statement and link to the online survey was either sent via student email system or advertised on the relevant intranet site of the university depending on the institution's policy (Additional File 1). Students were provided with the aims of the research and information regarding their voluntary participation, right to withdraw and the anonymity of the results. By participating, the students consented to the study.

\section{Materials}

Two online questionnaires were designed, one for assessing breastfeeding education provided within the curriculum and the other to determine their students' knowledge and perceptions (Additional File 2). Data was collected from curriculum staff relating to the type of education offered and in which year groups and modules this was delivered. Student questionnaires collected data on demographics, their confidence in supporting breastfeeding mothers, the perceived role of doctors in breastfeeding support, career aspirations, and interest in receiving additional teaching on breastfeeding. Questions included multiple choice, ranked answers and Likert scales.

\section{Data analysis}

Microsoft Excel was used for the collation of basic percentage data. IBM SPSS 24 statistical software was used for all other statistical analysis. For categorical data Pearson's Chi-squared test was used to determine significant differences between groups. For non-parametric data, the Mann-Whitney U Test was used. P-values $<0.05$ 
were considered significant. Histograms were used to determine the data distribution.

\section{Results \\ Participants}

In total, 26 out of 32 eligible medical schools completed the initial online curriculum survey between March 2017 and September 2017. 25 out of 30 eligible medical schools consented for their students to be surveyed, with participation from medical students at 22 out of 25 consented universities. Overall, 411 medical students in their penultimate and final years of study participated in the online survey between March 2017 and March 2018. There was a median of $13(3.25,27)$ student participants per medical school.

\section{Medical school education}

Curriculum data on $81 \%(26 / 32)$ of the eligible UK undergraduate medical schools was collected with regards to breastfeeding education (Table 1). 85\% (22/26) of participating medical schools provided compulsory breastfeeding teaching (with the requirement that all students attend), three provided optional teaching and one did not include any breastfeeding education in their curriculum. Over three-quarters $(81 \%)$ of the medical schools provided lectures on breastfeeding, with around two-fifths (46\%) delivering seminars or small group teaching. Lectures were often provided in a pre-clinical context focusing on lactation physiology, whereas clinical exposure was usually with the postnatal midwifery team. Often this was unstructured and delivered on an ad hoc basis. Formal clinical teaching on breastfeeding is provided at five (19\%) medical schools as part of general practice, paediatrics and obstetric modules. Details of the different teaching methods are available in the supplementary materials (Additional File 3).

\section{Medical student characteristics}

Table 2 presents the demographic data from the 411 student participants in our online survey. Over twothirds of the students were female $(72 \%, n=295)$ and $82 \%(n=336)$ were interested in a career in either obstetrics and gynaecology, paediatrics or general practice.

Table 1 Medical school curriculum

\begin{tabular}{ll}
\hline Overview & $n(\%)$ \\
\hline No. universities consenting to curriculum survey & $26 / 32(81)$ \\
Provide compulsory breastfeeding education & $22(85)$ \\
Lecture-based teaching & $21(81)$ \\
Seminars/ small group teaching & $12(46)$ \\
Formal clinical teaching & $5 / 26(19)$ \\
Ad hoc clinical teaching/ experience & $15 / 26(58)$ \\
\hline
\end{tabular}

$84 \%(n=347)$ of our medical student responders were aged between 21 and 25 years old.

\section{Breastfeeding knowledge of medical students}

In order to assess knowledge of the benefits of breastfeeding, medical students were asked to select from a list of given statements (Additional File 4). Overall, 92\% were able to successfully recognise that breastmilk contains antibodies and hormones. Other correct options identified from the list included: emotional attachment (97\%), reduced infantile infections $(90 \%)$, reduced maternal risk of breast and ovarian cancer (78\%), reduced risk of obesity and type II diabetes mellitus in adulthood (77\%), reduced risk of necrotising enterocolitis (69\%) and reduced environmental impact (62\%).

\section{Medical student clinical confidence}

Students were asked to self-assess their confidence in performing breastfeeding related clinical skills (Fig. 1). Across the three skills, a minority of medical students assessed themselves as confident. $16 \%(n=66)$ felt confident at recognising and managing mastitis and nipple thrush, $13 \%(n=53)$ were confident they could advise on medical reasons for supplementing breastfed infants with formula, and only $3 \%(n=14)$ were confident in assisting with latching. Receiving compulsory breastfeeding teaching was not significantly associated with students' self-rated skills performance, however students who had received formal clinical teaching $(p=0.04)$ or small group teaching $(p<0.01)$ had significantly more confidence at diagnosing and managing nipple problems (Additional File 5).

\section{Doctors' role in breastfeeding}

Medical students were asked to rank six categories of influencer with respect to how influential they are upon infant feeding decisions of mothers (Table 3). Partners were ranked as most influential with the doctor ranked fourth out of six. Student career aspirations had no effect upon the mean ranked score (Additional File 6). Overall, $44 \%$ thought doctors played a very important role in breastfeeding support, $49 \%$ viewed it as quite important, and only $7 \%$ thought it was not within the remit of the doctor. Medical students who had a career interest in either obstetrics and gynaecology, paediatrics or general practice perceived the doctors' role in breastfeeding support as more important $(p=0.01$; Additional File 7). Student gender and teaching received at medical school were not statistically associated with their perceived importance of supporting breastfeeding as a clinician. 
Table 2 Medical student characteristics $(n=411)$

\begin{tabular}{ll}
\hline Demographic details & $n(\%)$ \\
\hline Male & $116(28)$ \\
Female & $295(72)$ \\
Age (years) & \\
$21-25$ & $347(84)$ \\
$26-30$ & $46(11)$ \\
$31-35$ & $9(2)$ \\
$>36$ & $9(2)$ \\
Had a career interest in obstetrics and gynaecology, & $336(82)$ \\
paediatrics and/or general practice & 148 \\
$\quad$ Obstetrics and gynaecology & 160 \\
Paediatrics & 244 \\
$\quad$ General practice & 117 \\
Number of students with career interests in more than \\
one of the given specialities
\end{tabular}

\section{Medical student attitudes towards further breastfeeding education}

Overall, 93\% (381/411) of students surveyed stated they would like more training on breastfeeding within the undergraduate medical school curriculum. 9\% $(n=26)$ required lecture-based teaching, 19\% $(n=78)$ preferred practical skills training, whereas the most favoured teaching approach was a combined approach $(65 \%, n=267)$.

There were no statistical differences in student desire to receive further breastfeeding education with regards to their self-assessed skill confidence. However, of the students requesting teaching by combined methods, there was lower confidence in nipple management $(p<$ $0.01)$ and formula use ( $p=0.01$, Additional File 8$)$.

\section{Discussion}

\section{The medical school curriculum}

This is the first study to date looking at the inclusion of breastfeeding education within the undergraduate medical school curriculum in the UK. Currently, there is no standardised approach to the content and structure of the teaching provided, with $15 \%$ of the participating institutions providing no compulsory breastfeeding education. These findings were also reflected in the USA $[20,21]$. An indepth analysis of the curriculum at the United States Medical Institution revealed training deficits in both knowledge and skills-based competencies, which was reflected in their students' self-rated breastfeeding knowledge and counselling abilities [22]. Furthermore, insufficient inclusion of breastfeeding within the undergraduate curricula has also been reported in Korea, with a lack of interactive learning opportunities and clinical exposure [23].

The Academy of Breastfeeding Medicine (ABM), a global organisation of physicians, produced an education statement on the learning objectives related to human lactation [24]. In line with the Baby Friendly Initiative, medical schools should aim to educate their students in both the theory and practice of breastfeeding. According to $\mathrm{ABM}$, it is recommended that all students receive clinical training in the management of breastfeeding. Relevant skills to be covered included safe prescribing for breastfeeding, the facilitation of latching, counselling mothers and managing common problems [24]. Our

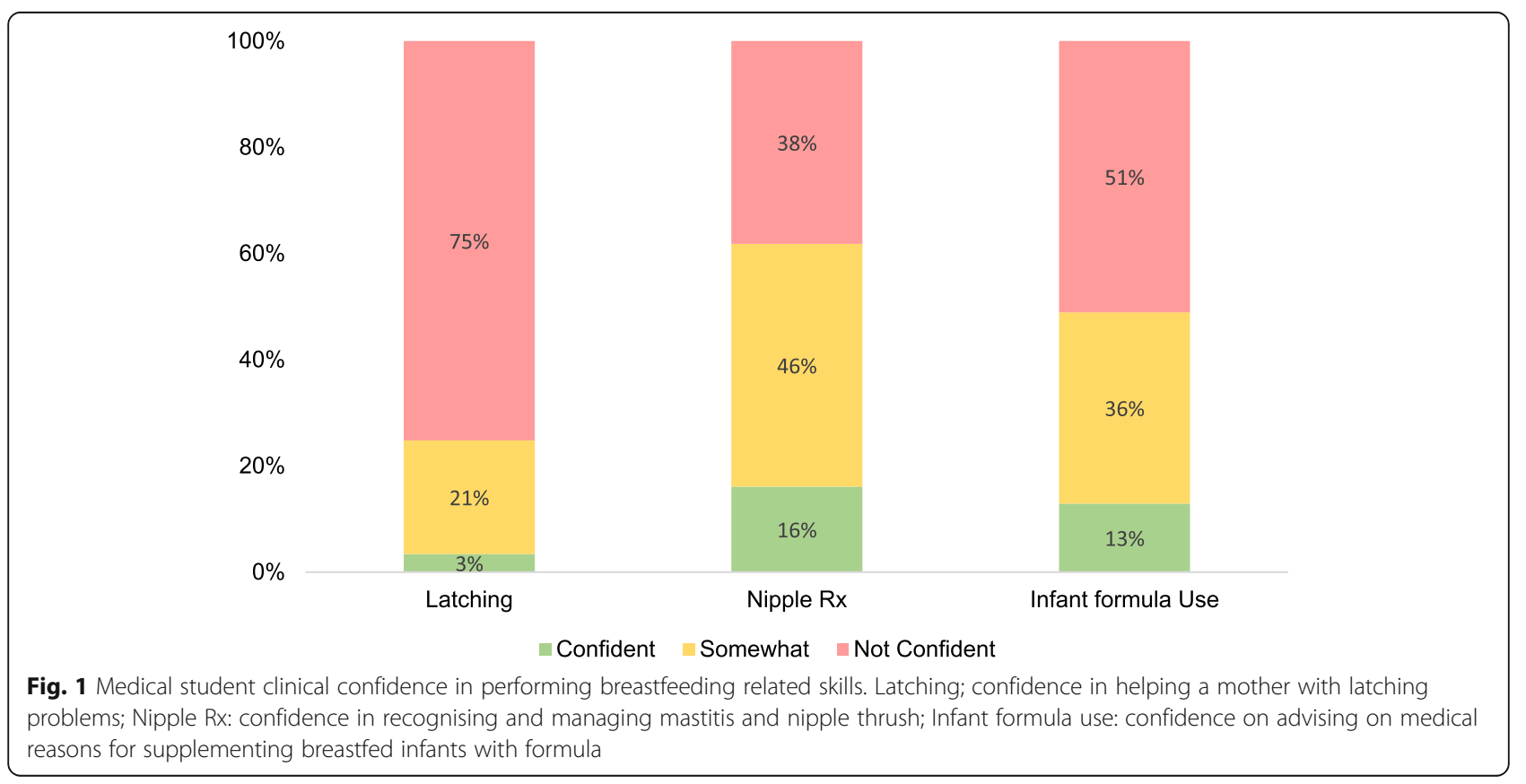


Table 3 Medical students' ranked perceptions of which figure is most influential upon a mother's infant feeding decisions

\begin{tabular}{ll}
\hline & Mean ranking (1-6) \\
\hline Partner & 2.39 \\
Midwife & 2.6 \\
Mother & 3.01 \\
Doctor & 3.76 \\
Other family member & 4.4 \\
Other healthcare professional & 4.8 \\
\hline
\end{tabular}

1: most influential; 6: least influential

study found that only $19 \%$ of institutions provided formal clinical exposure or training on breastfeeding.

\section{Are medical students ready to support breastfeeding?}

In this study, we collected data on the preparation of medical students for supporting breastfeeding mothers. When provided with a list of true/false statements, students performed well at identifying the benefits of breastfeeding (Additional File 4). This was often covered in the lecture-based teaching, provided by most medical schools. Although students felt prepared to identify benefits of breastfeeding, their confidence to perform breastfeeding skills was low.. This is concordant with a systematic review of healthcare students demonstrating insufficient breastfeeding knowledge regarding assessment and management of breastfeeding-related issues [25]. A study in the USA found $100 \%$ nursing students were able to identify breastmilk as the optimum feeding choice, however $65 \%$ were unable to identify cracked nipples as a potential indication poor latching, with $62 \%$ believing cracked nipples are managed by expressing milk and refraining from breastfeeding for $24 \mathrm{~h}$ [26].

The General Medical Council's 'Outcomes for Graduates' states that new doctors must be competent in providing explanation, advice and support to address their patients' needs [27]. The students in our study recognised the role of the doctor in supporting breastfeeding. This was particularly the case in students with a career interest in either obstetrics and gynaecology, GP or paediatrics. However, according to the Educational Objectives and Skills for the Physician with Respect to Breastfeeding, outlined by ABM, "All physicians, regardless of discipline, should have basic knowledge and skills in breastfeeding maintenance, diagnosis, and treatment of related problems" [24].

Although students did not perceive the doctor to be the most influential figure in infant feeding decisions, their role in promoting breastfeeding was recognised. This view is supported in a study by Odom et al., with women naming the infant's father, the maternal grandmother, and doctor as important figures [28]. Despite this, healthcare professionals may often underestimate their impact on such decisions. In a Scottish study, NHS staff felt their contribution to breastfeeding support were diminished due to external factors, with family members playing a much greater role, than the professional, in infant feeding decisions [29].

\section{Improving breastfeeding education}

The majority (93\%) of the students participating in our study stated they would like more teaching on breastfeeding at medical school. The perceived value of including undergraduate breastfeeding education is not a new viewpoint. A survey from the 1970s suggesting half of paediatricians and obstetricians would have benefited from a specific breastfeeding curriculum whilst at medical school [30]. This view is still relevant today with 85\% Norwegian GPs believing that infant feeding should be taught before gaining their registration [12]. Additionally, doctors who reported lower confidence in breastfeeding clinical skills were less likely to engage with further training, suggesting the need to incorporate breastfeeding into a core curriculum [13].

The introduction of breastfeeding education is wellreceived by staff and students [31]. A medical school in New Mexico developed a module to include interactive teaching and patient visits, delivered via a multi-specialty approach [21]. In another example, $88 \%$ of medical students in India showed awareness of the BFI 'ten steps of successful breastfeeding' which was taught as part of the core curriculum and demonstrated successful integration into medical education [19]. A study of Brazilian healthcare students and professors have however identified the potential impracticalities of integrating breastfeeding into the already full-time undergraduate curriculum, with particular stress on the requirement for more practical classes on breastfeeding [32].

The medical students in our sample desired an integrated learning approach to include both theoretical knowledge and practical skills. The value of this teaching style is emphasised in the Carnegie Foundation for the Advancement of Teaching report [33]. A breastfeeding toolkit was developed with theoretical material for nursing students, however there was no statistical improvement in knowledge [34]. In addition, Taiwanese nursing students felt their theoretical training insufficiently prepared them to support mothers [35].

A recent Indonesian study demonstrated greater knowledge and counselling skills in final year students who had participated in an integrated module including hands-on teaching [18]. The successful implementation of breastfeeding roleplay intervention for healthcare volunteers was also demonstrated in Iran, with greater persisting knowledge and transfer of emotional experiences when compared to lecture-based education [36]. Our results support this finding with students who had 
received formal clinical teaching and/or small group sessions describing greater confidence in managing nipple pathology.

In the USA, a high-fidelity lactation simulation model was developed for educating healthcare professionals. During a development trial, physician residents reported benefits of being able to practice comfortable hand positioning during the breast assessment. Breastfeeding medicine physicians and midwifery students evaluated the final model as having realistic representations of lactation-related pathology and an effective breast pump mechanism to simulate hand expressing [37].

A recent scoping review of application-based breastfeeding education for nurses and physicians demonstrated a variety of teaching methods using real patients and roleplay, but found no standardised method of educational intervention or evaluation [38]. Several teaching methods have been suggested to provide an integrated breastfeeding education for the undergraduate medical student. These include online components, problembased learning (PBL) and Objective Structured Clinical Examinations (OSCEs) [23]. A case-study in Lebanon has also identified the role of social networking in breastfeeding education to promote medical students self-efficacy and knowledge [39].

As there is a clear association between examinations and students' learning, the ABM guidance stresses the additional importance of including breastfeeding in examinations to ensure students dedicate their efforts at learning the relevant material $[40,41]$.

\section{Limitations}

The main limitation of this study was the inability to collect data from all UK undergraduate medical schools due to institutional permissions. The curriculum survey was completed by an allocated member of university staff; however, the response given may have varied depending on their role within the university. The majority of medical student respondents were female (Table 2, $72 \%$ ), however this does reflect the national 3:2 ratio of female to male students in UK medical schools [42]. A recent study of GP registrars found that males doctors presumed that women with BF problems would want to see a female GP [11], which may infer that there is a perception among male trainees that this field is not relevant to them. Given the potential for all doctors to encounter breastfeeding mothers and influence infant feeding decisions, further work is needed to ensure skills that support the establishment and maintenance of breastfeeding engage all trainees.

\section{Conclusions}

The current level of breastfeeding education within the curriculum at UK undergraduate medical schools is insufficient, with few able to ensure that their students gain adequate clinical exposure. This may be related to either lack of time or lack of priority in the curriculum. From this study and the literature, doctors play an important role in supporting breastfeeding, but medical students in their penultimate years of study do not feel adequately prepared to fulfil this role. Further studies should explore the competency of doctors to meet the needs of lactating women, and design optimal training for UK medical students. Our results and the existing literature suggest that an integrated core curriculum to include practical training is both necessary and imperative. With the advent of relatively cheap breastfeeding simulation for teaching systems this should now be feasible in most medical schools.

\section{Supplementary information}

Supplementary information accompanies this paper at https://doi.org/10. 1186/s13006-020-00290-z.

Additional file 1. Patient Information Sheet. Word document.

Additional file 2. Survey questions on SurveyMonkey. Word document. Additional file 3. Medical school curriculum details. Word document.

Additional file 4. Table of medical students' ability to correctly identify the benefits of breastfeeding (Table). Word document.

Additional file 5. Medical students self-rated confidence in clinical skills in relation to teaching provided by medical school (Table). Word document.

Additional file 6. Ranking of influential figures according to interest in obstetrics and gynaecology/paediatrics/general practice (Table). Word document.

Additional file 7. Influences upon medical students' perceived importance of the doctor's role in Breastfeeding support (Table). Word document.

Additional file 8. Interest in further teaching in medical schools according to medical students' confidence at performing breastfeedingrelated skills (Table). Word document.

\section{Notes on contributors}

Dr. Kirsty Biggs is an Academic Foundation Year One Doctor at University Hospital North Midlands. She developed an interest in breastfeeding during her BSc in Reproductive and Developmental Science at Imperial College London and strives to improve breastfeeding education within the UK medical school curriculum.

Dr. Katy Fidler is a Consultant Paediatrician and Senior Lecturer in Paediatrics at Brighton and Sussex Medical School and Lead for the undergraduate paediatric curriculum at BSMS. She supports a diverse range of teaching in paediatrics and recognizes the importance of breastfeeding education as part of this. Dr. Natalie Shenker is a UKRI Future Leaders Fellow and cofounder of the Human Milk Foundation, which supports more families to feed their babies with human milk. The charity is enhancing access to screened donor milk when breastfeeding is impossible or delayed.

Miss Heather Brown is a Consultant Obstetrician Gynaecologist and Senior Clinical Lecturer in Obstetrics and Gynaecology at Brighton and Sussex Medical School and Deputy Medical Director for Brighton and Sussex University Hospitals Trust. She has an active role in developing and delivering the undergraduate curriculum and in postgraduate teaching. 
to the writing of the manuscript. The author(s) read and approved the final manuscript.

\section{Funding}

No external funding source supported this study.

\section{Availability of data and materials}

All data generated or analysed during this study are included in this published article [and its supplementary information files].

\section{Ethics approval and consent to participate}

Ethical approval was gained via the Brighton and Sussex Medical School Research Governance \& Ethics Committee (Ref no. 17/020/BRO) on 06/03/2017.

\section{Consent for publication}

Not applicable.

\section{Competing interests}

NS is funded by a UKRI Future Leaders Fellowship at Imperial College London and is a non-remunerated Trustee of the Human Milk Foundation.

\section{Author details}

${ }^{1}$ Royal Stoke University Hospital, Newcastle Road, Stoke-on-Trent ST4 6QG, UK. ${ }^{2}$ Brighton and Sussex Medical School, Falmer BN1 9PX, UK. ${ }^{3}$ Department of Surgery and Cancer, Imperial College London, IRDB Hammersmith Hospital, London W12 OHS, UK.

\section{Received: 22 November 2019 Accepted: 11 May 2020 Published online: 20 May 2020}

\section{References}

1. Rollins NC, Bhandari N, Hajeebhoy N, Horton S, Lutter CK, Martines JC, et al. Why invest, and what it will take to improve breastfeeding practices? Lancet. 2016:387(10017):491-504.

2. Victora CG, Bahl R, Barros AJ, França GV, Horton S, Krasevec J, et al. Breastfeeding in the 21st century: epidemiology, mechanisms, and lifelong effect. Lancet. 2016;387(10017):475-90.

3. Andreas NJ, Kampmann B, Mehring L-DK. Human breast milk: a review on its composition and bioactivity. Early Hum Dev. 2015;91(11):629-35.

4. Health and Social Care Information Centre. Infant Feeding Survey 2010 [Available from: http://www.hscic.gov.uk/catalogue/PUB08694] Accessed 04/ 03/2020.

5. WHO. Baby Friendly Hospital Initiative 2009 [Available from: https://www. who.int/nutrition/topics/bfhi/en/] Accessed 04/03/2020.

6. Britton C, McCormick FM, Renfrew MJ, Wade A, King SE. Support for breastfeeding mothers. Cochrane Database Syst Rev. 2007;1:CD001141.

7. Brodribb W, Fallon T, Jackson C, Hegney D. Attitudes to infant feeding decision-making--a mixed-methods study of Australian medical students and GP registrars. Breastfeed Rev. 2010;18(1):5-13.

8. Ingram J. Multiprofessional training for breastfeeding management in primary care in the UK. Int Breastfeed J. 2006:1:9.

9. Burt S, Whitmore M, Vearncombe D, Dykes F. The development and delivery of a practice-based breastfeeding education package for general practitioners in the UK. Matern Child Nutr. 2006:2(2):91-102.

10. Finneran B, Murphy K. Breast is best for GPs--or is it? Breastfeeding attitudes and practice of general practitioners in the mid-west of Ireland. Ir Med J. 2004;97(9):268-70

11. Brodribb WE, Jackson C, Fallon AB, Hegney D. Gender and personal breastfeeding experience of rural GP registrars in Australia--a qualitative study of their effect on breastfeeding attitudes and knowledge. Rural Remote Health. 2007;7(3):737.

12. Svendby HR, Løland BF, Omtvedt M, Holmsen ST, Lagerløv P. Norwegian general practitioners' knowledge and beliefs about breastfeeding, and their self-rated ability as breastfeeding counsellor. Scand J Prim Health Care 2016:34(2):122-9.

13. Wallace LM, Kosmala-Anderson J. A training needs survey of doctors' breastfeeding support skills in England. Matern Child Nutr. 2006;2(4):217-31.

14. Taveras EM, Li R, Grummer-Strawn L, Richardson M, Marshall R, Rêgo VH, et al. Opinions and practices of clinicians associated with continuation of exclusive breastfeeding. Pediatrics. 2004;113(4):e283-90.
15. Harden RM. Ten key features of the future medical school-not an impossible dream. Med Teach. 2018:40(10):1010-5.

16. Boroumand S, Stein MJ, Jay M, Shen JW, Hirsh M, Dharamsi S. Addressing the health advocate role in medical education. BMC Med Educ. 2020;20:28

17. Anjum Q, Ashfaq T, Siddiqui $H$. Knowledge regarding breastfeeding practices among medical students of Ziauddin University Karachi. J Pak Med Assoc. 2007;57:480-3.

18. Sjarif DR, Yuliarti K, Wahyuni LK, Wiguna T, Prawitasari T, Devaera $Y$, et al. Effectiveness of a comprehensive integrated module using interactive lectures and workshops in understanding and knowledge retention about infant feeding practice in fifth year medical students: a quasi-experimental study. BMC Med Educ. 2016;16:210.

19. Kakrani VA, Rathod Waghela HK, Mammulwar MS, Bhawalkar JS. Awareness about "ten steps for successful breastfeeding" among medical and nursing students. Int J Prev Med. 2015:6:40.

20. Taylor JS, Bell E. Medical education and leadership in breastfeeding medicine. Breastfeed Med. 2017:12(8):476-8

21. Ogburn T, Espey E, Leeman L, Alvarez K. A breastfeeding curriculum for residents and medical students: a multidisciplinary approach. J Hum Lact. 2005;21(4):458-64

22. Gary AJ, Birmingham EE, Jones LB. Improving breastfeeding medicine in undergraduate medical education: a student survey and extensive curriculum review with suggestions for improvement. Educ Health (Abingdon). 2017;30(2):163-8

23. Kim YJ. Important role of medical training curriculum to promote the rate of human milk feeding. Pediatr Gastroenterol Hepatol Nutr. 2017;20(3):147-52.

24. Meek JY. Academy of breastfeeding medicine. Educational objectives and skills for the physician with respect to breastfeeding. Breastfeed Med. 2011; 6(2):99-105.

25. Yang SF, Salamonson Y, Burns E, Schmied V. Breastfeeding knowledge and attitudes of health professional students: a systematic review. Int Breastfeed J. 2018;13:8

26. Ahmed A. el-Guindy SR. breastfeeding knowledge and attitudes among Egyptian baccalaureate students. Int Nurs Rev. 2011;58(3):372-8.

27. General Medical Council. Outcomes for graduates 2018 [Available from: https://www.gmc-uk.org/-/media/documents/dc11326-outcomes-forgraduates-2018_pdf-75040796.pdf]. Accessed 04/03/2020.

28. Odom EC, Li R, Scanlon KS, Perrine CG, Grummer-Strawn L. Association of family and health care provider opinion on infant feeding with mother's breastfeeding decision. J Acad Nutr Diet. 2014;114(8):1203-7.

29. Marks D, O'Connor R. Health professionals' attitudes towards the promotion of breastfeeding. Br J Midwifery. 2015;23(1):50-8.

30. Hollen BK. Attitudes and practices of physicians concerning breastfeeding and its management. J Trop Pediatr Environ Child Health. 1976; 22(6):288-93.

31. Chen $\mathrm{CH}$, Shu HQ, Chi CS. Breastfeeding knowledge and attitudes of health professionals and students. Acta Paediatr Taiwan. 2001:42(4):207-11.

32. Viaro VD, Linhares FMP, Marinus MWLC, Guedes TG, Vanderley LSL. Limits and possibilities for teaching and learning about breastfeeding. Rev Bras Enferm. 2019;72(1):3-8

33. Irby D. Educating physicians for the future: Carnegie's calls for reform. Med Teach. 2011;33(7):547-50

34. Folker-Maglaya C, Pylman ME, Couch KA, Spatz DL, Marzalik PR Implementing a breastfeeding toolkit for nursing education. J Perinat Neonatal Nurs. 2018:32(2):153-63.

35. Yang SF, Burns E, Salamonson Y, Schmied V. Expectations and experiences of nursing students in supporting new mothers to breastfeed: a descriptive qualitative study. J Clin Nurs. 2019;28(11-12):2340-50.

36. Vizeshfar F, Zare M, Keshtkaran Z. Role-play versus lecture methods in community health volunteers. Nurse Educ Today. 2019:79:175-9.

37. Sadovnikova A, Chuisano SA, Ma K, Grabowski A, Stanley KP, Mitchell KB, et al. Development and evaluation of a high-fidelity lactation simulation model for health professional breastfeeding education. Int Breastfeed J. 2020;15:8.

38. Chuisano SA, Anderson OS. Assessing application-based breastfeeding education for physicians and nurses: a scoping review. J Hum Lact. 2019: 890334419848414. https://doi.org/10.1177/0890334419848414.

39. Moukarzel S, Mamas C, Warstadt MF, Bode L, Farhat A, Abi Abboud A, et al. A case study on breastfeeding education in Lebanon's public medical school: exploring the potential role of social networks in medical education. Med Educ Online. 2018;23(1):1527629. 
40. Sam AH, Wilson RK, Lupton M, Melville C, Halse O, Harris J, et al. Clinical prioritisation questions: a novel assessment tool to encourage tolerance of uncertainty? Med Teach. 2020;42(4):416-21.

41. Van Etten S, Freebern G, Pressley M. College students' beliefs about exam preparation. Contemp Educ Psychol. 1997;22(2):192-212.

42. Moberly T. Number of women entering medical school rises after a decade in decline. BMJ. 2018;363:k4098.

\section{Publisher's Note}

Springer Nature remains neutral with regard to jurisdictional claims in published maps and institutional affiliations.

Ready to submit your research? Choose BMC and benefit from:

- fast, convenient online submission

- thorough peer review by experienced researchers in your field

- rapid publication on acceptance

- support for research data, including large and complex data types

- gold Open Access which fosters wider collaboration and increased citations

- maximum visibility for your research: over $100 \mathrm{M}$ website views per year

At $\mathrm{BMC}$, research is always in progress.

Learn more biomedcentral.com/submissions 